\title{
Telemedicine in cardiology - prospects, risks and health inequalities
}

\author{
Paweł Gorczyński', Marta Primke', Szymon Czmoch'1, Katarzyna Śniatała', Łukasz Żytka', \\ Danuta Misiuvianets' ${ }^{1}$, Violetta Naughton ${ }^{2}$, Teresa Grzelak ${ }^{3}$ \\ 'Medical Student Group, Poznań University of Medical Sciences, Poland \\ 2Biomedical Sciences Research Institute Ulster University, Coleraine, Northern Ireland, United Kingdom \\ ${ }^{3}$ Chair and Department of Physiology, Poznań University of Medical Sciences, Poland
}

\begin{abstract}
Telemedicine is an increasingly well-established area of health care that uses information technology to provide remote consultation and health support to patients. Most recently, it is of particular importance due to the COVID-19 pandemic. Notably, technological developments have allowed this form of health care provision to increase in scope and diversify the support provided to patients. Such broadening of scope and diversification of health care provision is particularly prominent in cardiology. It includes primary and secondary teleconsultations, remote monitoring of cardiological (including geriatric) patients by recording and monitoring electrocardiogram records, monitoring cardiac implantable electronic devices, telerehabilitation and tele-education. Moreover, in cardiology, telemedicine provides patients with feasible access to health care professionals while potentially reducing the cost to the health care providers. This article presents a critical evaluation of current applications of telemedicine in cardiology based on the literature. It highlights the advantages, disadvantages and inequalities of this form of cardiological healthcare provision.
\end{abstract}

KEY WORDS: telemedicine, e-learning, cardiology, telerehabilitation, health inequalities, teleconsultations, technological innovations.

ADDRESS FOR CORRESPONDENCE: dr Teresa Grzelak, Chair and Department of Physiology, Poznań University of Medical Sciences, Poland, e-mail: tgrzelak@ump.edu.pl

\section{INTRODUCTION}

The most important factor reducing the risk of dangerous complications of various cardiovascular diseases (CVD) (e.g. sequelae of myocardial ischaemia) is a quick and accurate diagnosis followed by proper medical support. For fast and professional therapy to be possible it is necessary to collect the relevant information which constitutes the basis to make the right decisions. Telemedicine - one of the strongly developing branches of medicine - is helpful in such cases. The utilisation of the different technical innovations enables quick reaction and more effective help to the cardiac patients in need, especially when what is the most important is the time from the occurrence of the symptoms to providing medical aid. However, modern methods also have certain disadvantages connected to the lack of direct contact between the medical staff and the patient as well as financial or organisational barriers. The aim of the following review article is to sum up, and systematise the knowledge about the currently used or promising telemedical solutions in cardiology as well as to describe their advantages and potential disadvantages. We analysed the English language PubMed databases using the following keywords: Telemedicine (cardiology, cardiac care, heart failure, cardiovascular); Tele-echocardiography; Cardiac teleconsultation; eHealth in cardiology; Telehealth in cardiology; Cardiovascular telemonitoring; Telerehabilitation in cardiology; Mobile technology in cardiology; Home technology in cardiology; Electronic heart implant devices; E-learning in cardiology; Electronic education 
in cardiology. For the literature review, full-text articles from the last ten years were considered to obtain the most up-to-date information. We focused on the literature items in the following order: meta-analyses, original articles based on large cohorts, randomized studies, double-blind studies. Full-text articles from the last ten years were considered to obtain the most up-to-date information. The article is divided into the following sections: cardiological teleconsulting, remote electrocardiogram (ECG) monitoring, telemonitoring of cardiac implantable electronic devices (CIED), geriatric cardiological patients' telesupervision, telerehabilitation of cardiac patients and tele-education in cardiology. Technical and social aspects were included in the paper only when necessary to understand the clinical problems.

\section{CARDIOLOGICAL TELECONSULTING}

The simplest form of cardio telemonitoring for people with a high risk of cardiovascular events are phone calls scheduled according to patients' requirements. During these calls, a specialist conducts an interview, which complements the telesupervision (the data collected and transmitted from the devices installed on a patient). The available apparatuses can monitor different symptoms, i.e. chest pain, fatigue, apnoea, swelling, and other parameters such as pulse, blood pressure, weight (important not only in the case of overweight/ obesity - a major risk factor of cardiovascular diseases) as well as electrical changes in the heart. The telemonitoring tools can be classified as external stationary, portable or implantable devices. After data transmission, further processing can be done automatically via specialized software based on artificial intelligence algorithms [1,2] or traditionally through a doctor's analysis. Teleconsulting is one of the innovative forms of remote communication between health care professionals or between health care professionals and patients. Notably, this developing technology is particularly helpful in urgent consultations, often required in emergency medicine. Furthermore, online meetings are becoming more and more popular among international experts to share knowledge and support decision making regarding care provided to patients. Such meetings allow for feasible sharing of patients' data obtained e.g. during the diagnostics or therapy (while assuring patients' confidentiality) to establish the best possible treatment option of an individual patient. Teleconsulting is also currently more often used for the primary consultations [3]. Its role became even more important during the COVID-19 pandemic, when direct, physical contact with people was reduced [4]. More recent telemedical innovations enable remote assessment of patients' clinical condition based on previously obtained recordings of daily measurements such as ECG [5] using various wearable electronics [6]. Increased feasibility of teleconsultations in recent years occurs due to the dynamic development of remote data transmission systems which provided the technological foundation for the efficient teleconsulting systems dedicated to cardiology [5]. Current cardiological consultations, for example, allow for remote and fast-tracked assessment of patients experiencing chest pain allowing for the informed decision of further treatment or transportation to the nearest cardiological or outpatient clinic. Such a cardiological teleconsulting system (remote cardio consultation) significantly decreases the time required to make a proper diagnosis and to start adequate therapy [7]. Additionally, it reduces the total costs of diagnostics, treatment, rehabilitation or absence from work.

A critical issue which must be taken into consideration in telemedicine systems is the provision of proper security of the transmitted data [5, 8]. Rao et al. [8] described the medical images of encryption procedures. These issues are related to the existing legal regulations which protect patients' sensitive data. A lack of direct contact with a patient makes impossible either their physical examination or instant medical help in case of emergency. Another limitation is the fact that development of such innovations requires proper hardware and software, and the personnel involved in this type of health care must be trained to gain appropriate knowledge and competence to use the latest technology [5].

Heart disease has become one of the most hazardous diseases. According to the World Health Organization, around 17.9 million people globally die due to CVDs every year. New technologies allow the improvement of telemedicine. The paper presents some aspects of telecardiology, which is a modern medical practice that uses the power of telecommunication to achieve the remote diagnosis and treatment of heart disease.

\section{REMOTE ELECTROCARDIOGRAM MONITORING}

In cardiology, remote ECG monitoring enables faster and more accurate diagnoses of CVD. However, some patients, e.g. the elderly, may find operating electronic devices used for ECG monitoring difficult $[5,9]$. Therefore, telesupervisory equipment should be as simple to use as possible. Conducting analyses remotely could improve the patients' quality of life by reducing the number of hospitalisations and quickening the process of contacting a doctor. Electrocardiographic telemonitoring, as a fundamental telemedical tool in cardiology, allows detection and analysis of the abnormal electrical activity of the heart beyond the hospital, during daily activity. This system conducts an ECG reading and sends the records to a supervision centre for interpretation. Activation of the device by a patient who has experienced disturbing symptoms is a preferred method of saving data. The apparatus also saves measurements from before being triggered by the patient, which prevents loss of information about short abnormalities. There are also implantable recorders which 
are used when long-term usage of an external monitor is impossible and symptoms are occasional. The analyses showed that telesupervision which requires a patient only to place electrodes and contact a supervision centre is simple enough to be implemented for elderly people [5].

The results of a prospective study by Halcox et al. on a population of 1001 patients over 65 years of age, 500 of whom were remotely monitored with an AliveCorKardia device and 501 were routinely checked up by doctors, showed an almost fourfold increase in the percentage of correct atrial fibrillation (AF) diagnosis in the tele-monitored group over the year [10]. Halcox et al. used telemonitoring for the recording of 1-lead ECG fragments twice a week for 12 months, with additional measurements taken whenever any alarming symptoms occurred. Aside from the improved diagnostics, Halcox et al. reported that the study participants who had been provided with remote cardio-care showed increased awareness and decreased anxiety related to the abnormal heartbeat and its pathophysiological implications (e.g. myocardial infarction). Furthermore, the patients in regular, standard health care in the Halcox et al. study showed willingness to change the method of their medical supervision to remote care.

Research conducted in Brazil allowed detection of 304 sudden heart rhythm disorders based on data obtained using remote ECG [11]. In the study by Marcolino et al., the ECG tests were recorded in primary care clinics and with additional information about patients and forwarded to the Telehealth Network of Minas Gerais - a public telemedical service where the records were interpreted by the consultants' cardiologists. The diagnosis by the consultant cardiologists allowed further treatment to be determined. It was revealed that in the case of uncertainty of clinical tests and symptoms interpretation, the records should be analysed by specialists. Otherwise, wrong diagnoses made by primary care doctors ( $29 \%$ of cases in Brazilian research) could lead to delays in treatment [11].

Transmission and interpretation of pre-hospital ECG records by cardiologists or emergency physicians have been used to provide quicker diagnoses. The publication showed the influence of such systems on reducing the hospital mortality rate in either 30-day or long-term hospital observation of the patients after acute coronary syndrome. There has also been noted a shortening of door-to-balloon time (from admission to ER to heart catheterisation) [9].

Interesting analyses on the subject of people involved in remote diagnostics of abnormal heart rhythm and treatment effects were conducted in the Netherlands. Over the period from June 2017 to March 2018 on a population of adults with congenital heart diseases there was performed a study using telemonitoring of 1-lead ECG, blood pressure and weight measurements. Data sent via mobile applications were interpreted based on person- alised thresholds by nurses supervised by cardiologists. Measurements were taken twice per week with the possibility of sending additional data if any symptoms had occurred. The use of phone programmes simplified the control of treatment effectiveness, sped up the contact with a doctor and made it possible to take immediate action if the patient's condition had worsened. It was found that operating a telemedical application did not cause the participants any problems. However, lowering the quality of life, probably resulting from the time taken up by the telesupervision and facing one's disease more frequently than before, was one of the causes of refusing to participate in the study for some of those invited [12]. Novel devices which are more and more popular in tele-monitoring and tele-management include a different kind of mobile and implantable ones. The former include inter alia watches with heart rate, blood pressure measurement and/or ECG monitoring; dry wireless ECG electrodes with data transmission via Bluetooth or Wi-Fi and high-quality real-time monitoring (continuous or cyclic online analyses) [13]. Reliability tests were also passed by a low-power multi-lead wearable ECG signal sensor system meant for long-term multidimensional analysis of the electrical activity of the heart [14]. Independently from used facilities, it is important for developing this type of telesupervision to use highly advanced algorithms based on artificial intelligence for preliminary analysis of ECG records to differentiate the wide physiological range of heart activity from various types of abnormalities (e.g. supraventricular or ventricular arrhythmias). Such prepared data are sent to medium-level medical personnel, who in the case of an abnormal heart rhythm provide the information of the alarming event to the appropriate doctor. The majority of modern devices require data compression and fast processing of a large quantity of information using the newest technologies, which need significant financial resources $[13,14]$.

Remote ECG monitoring gives patients many benefits, such as improving their life quality and diagnosing heart rhythm abnormalities faster and more accurately. Nevertheless, it also has disadvantages. The systems may be difficult to use, especially for the elderly. Therefore, appropriate training is obligatory.

\section{TELEMONITORING OF CARDIAC IMPLANTABLE ELECTRONIC DEVICES}

Telemonitoring of CIED concerns patients who have had an artificial cardiac pacemaker, an implantable ECG recorder, an implantable cardioverter-defibrillator (ICD), or a device for cardiac resynchronization therapy (CRT) implanted. The Heart Rhythm Society as a class IA recommendation (where this type of treatment is beneficial and effective, which has been proven with strong evidence in multiple randomised clinical trials and meta-analyses) considers remote monitoring 
of CIED accompanied by at least one personal medical appointment within one year as well as proposing telemonitoring to every patient with an implanted device as a basic form of health state supervision [15]. This form of care is based on a home monitoring (HM) apparatus sending information collected from the implanted device via a cellular network to a server from which the data are shared (via the Internet) with health professionals in a secure way [5]. According to the European Society of Cardiology, in 2013 alone there were about 500000 artificial cardiac pacemakers, over 85000 ICDs and 50000 CRTs implanted [16]. The number of cardiological patients is still increasing, and therefore implantable electronic devices are used more often [3, 16]. Remote monitoring of patients enables early detection of AF or ventricular arrhythmia, assessment of treatment effectiveness and detection of disorders in the operation of the used device, for instance, a battery that is running out $[17,18]$. It is critically important in the case of children, as it has been previously shown that children are rarely aware of their symptoms or are not able to report them, especially when the events happen during sleep or physical activity [19]. In western countries, there are several remote monitoring systems available, e.g. HM (Biotronik), Medtronic CareLink Network, Boston Latitude, and St. Jude Merlin.net [5, 20]. The main difference between these systems is the frequency of data transmission. Home monitoring excels with its everyday information transfer whereas other listed systems share data cyclically, in defined periods of time. Previous studies by de Ruvo et al. and Kurek et al. have shown that application of the HM system increases the probability of detecting cardiac abnormalities, shortens the time to receive the diagnosis of the first event and enables the immediate reaction of health professionals in response to registered changes in the patient's condition $[20,21]$. However, it has to be noted that a correct technical configuration, leading to a higher connectivity level and more frequent transmission, has a positive impact on the effectiveness of remote monitoring $[3,20]$. Additionally, patients using HM can control episodes of arrhythmia continuously, without the necessity of frequent Holter examination [19]. According to the metaanalysis the HM system is more effective than telephone-based monitoring in improving the clinical outcomes and reducing all-cause mortality in patients with chronic heart failure [22]. Some of the studies show that telemonitoring of CIED leads to a decrease in the mortality rate of patients using this method of supervision compared to those under standard medical care. Kurek et al. reported that during both an annual and a threeyear observation among the remotely monitored people the mortality rate was significantly lower than in the control group [21]. Research conducted on patients with implanted CRT with defibrillation function also confirmed the decrease in the mortality rate in the group of remotely supervised people [23]. As mentioned earlier, the remote monitoring is intended to shorten the period of time between the occurrence of a cardiological abnormality and a clinical decision. Telemonitoring also aims at reducing the number of follow-up appointments and hospitalisations after implanting a cardiac device, as well as at shortening the time spent in the hospital, thus allowing a decrease in frequency and intensity of the health care services. The results of the published studies supporting the above postulations are presented in Table 1 below.

Furthermore, it can be suggested that telemonitoring allows prompt recognition and treatment of atrial fibrillation, hence potentially preventing further complications such as cardiac insufficiency or ischaemic brain stroke [24]. The reason for the lower hospitalization rate (which inter alia led to decreased costs for health care system) was probably the fact that arrhythmias and changes in the ST segment were detected sooner, which in turn led to a lower risk of complications. Lower costs for the patients were noticed due to no need for the treated person to commute frequently for additional tests and so their absence rate (from work) was decreased [25].

Notably, the results of the earlier REFORM trial showed that the patients who relied on remote everyday data transmission from an implanted device came for follow-up visits at one-year intervals instead of every three months, with no harm to their health. An elongation of this period leads to more frequent unplanned appointments due to uncertainty or general malaise of the monitored people. Nonetheless, the aggregate number of visits is significantly reduced. Additionally, patients who have more sporadic follow-up appointments tend to function in society better and their mental health improves [26]. The results of the Service User Technology Acceptability Questionnaire (SUTAQ), conducted on patients who had been using telemonitoring over a period of 12 months, showed that the patients reported a sensation of intensified care, accepted the method of the care provided and were overall satisfied with the remote care. Furthermore, the SUTAQ study showed that men, in comparison to women, were more positive about this form of health care [27].

The limitations of telemonitoring are related to the loss of data collected from the patients and the cost of a telemonitoring system (hardware, software, data storage, technical support). Is has been reported in the literature that the loss of data happens mostly due to patients accidentally turning off the monitoring device, a lack of data transmission, a patient's journey, disconnecting from the telephone line, discharging of a device battery or the need to restart the apparatus after a system crash $[19,24]$. Additionally, less frequent follow-up visits of the telemonitored people $[24,28]$ can turn out to be a risk for patients with multiple disorders. There is a concern that rarely conducted interviews and physical examination 
TABLE 1. Effects of telemonitoring in cardiac patients on the health care services $[17,21,23-25,26,28]$

\begin{tabular}{|c|c|c|}
\hline $\begin{array}{l}\text { First author, year } \\
\text { (name of the trial); } \\
\text { sample size }\end{array}$ & Outcome measures & Results \\
\hline $\begin{array}{l}\text { Crossley, } 2011[24] \\
(\text { CONNECT); } n=1997\end{array}$ & $\begin{array}{l}\text { - Median time from clinical } \\
\text { event to clinical decision } \\
\text { - Mean LOS per CV } \\
\text { hospitalisation visit } \\
\text { - Total clinic visits per year } \\
\text { - Total number of } \\
\text { hospitalisations } \\
\text { - Estimated mean cost per } \\
\text { hospitalisation }\end{array}$ & $\begin{array}{l}\text { - Telemonitoring required } \sim 4.6 \text { days while a standard/in-patient } \\
\text { assessment required } \sim 22 \text { days to reach a clinical decision }(p<0.001) \\
\text { - Mean LOS was significantly shorter ( } p=0.002) \text { in remotely controlled } \\
\text { group ( } 3.3 \text { days) compared to in-office arm ( } ~ 4 \text { days) } \\
\text { - The remotely controlled group had on average } 3.9 \text { appointments a year } \\
\text { while the conventionally supervised group had } 6.3 \text { appointments } \\
\text { - The difference in the number of hospitalisations was statistically } \\
\text { insignificant ( } p=0.524) \\
\text { - Estimated costs were } \$ 1,793(95 \% \mathrm{Cl}=1,644-1,940 \$) \text { lower } \\
\text { in the telemonitored arm }\end{array}$ \\
\hline $\begin{array}{l}\text { Landolina, } 2012 \text { [28] } \\
\text { (EVOLVO); } n=200\end{array}$ & $\begin{array}{l}\text { - Median time from an ICD } \\
\text { alert condition to clinical } \\
\text { decision } \\
\text { - Total urgent in-office visits }\end{array}$ & $\begin{array}{l}\text { - The treatment of patients who used remote systems of control was } \\
\text { instigated faster (on average } 1.4 \text { days); in conventionally treated } \\
\text { patients } ~ 24.8 \text { days were required }(p<0.001) \\
\text { - Remotely monitored patients with implanted ICD had } 35 \% \text { fewer } \\
\text { urgent visits than those who were not supervised with this method } \\
(p=0.005)\end{array}$ \\
\hline $\begin{array}{l}\text { Piccini, } 2016[51] \\
n=92566\end{array}$ & $\begin{array}{l}\text { - Risk of all-cause } \\
\text { hospitalisation } \\
\text { - Days spent in hospital per } \\
\text { year } \\
\text { - Hospitalisation cost per } \\
\text { patient-year }\end{array}$ & $\begin{array}{l}\text { - In remotely monitored arm the risk of hospitalisation was lower } \\
\text { (hazard ratio: } 0.82, \mathrm{Cl}=0.80-0.84, p<0.001) \\
\text { - Mean LOS in the hospital was reduced in the telemonitored arm } \\
\text { ( } 5.3 \pm 9.6 \text { days), compared to the standard arm }(8.1 \pm 15.7 \text { days; } \\
p<0.001) \\
\text { - Usage of telemonitoring enabled reduction of hospitalisation costs } \\
\text { per year by } 30 \%(p<0.001)\end{array}$ \\
\hline $\begin{array}{l}\text { Ricci, } 2017 \text { [25] } \\
\text { (TARIFF); } n=209\end{array}$ & $\begin{array}{l}\text { - Total number of in-hospital } \\
\text { follow-up visits per year } \\
\text { - Total number of } \\
\text { hospitalisations per year } \\
\text { - Mean LOS in hospital } \\
\text { - Mean costs for the health } \\
\text { care system } \\
\text { - Mean costs for patients }\end{array}$ & $\begin{array}{l}\text { - A lower aggregate number of appointments within one year } \\
\text { in the telemonitored group was noted ( } 58.78 \% \text { reduction; } \\
p<0.0001) \text {, regardless of the higher number of unplanned } \\
\text { remote visits } \\
\text { - The proportion of admissions to a hospital was reduced } \\
\text { in the remotely controlled group ( } 7 \text { vs. } 22 ; p=0.0032 \text { ), although there } \\
\text { was no difference in the length of the stay between groups ( } p=0.899 \text { ) } \\
\text { - Lower costs for both the health care system ( } 53.87 \% \text { reduction; } \\
p<0.0001 \text { ) and the patients ( } € 56.87 \pm € 80.22 \text { vs. } € 169.49 \pm € 189.50 \text {; } \\
p<0.0001 \text { ) were noted in the remotely monitored arm }\end{array}$ \\
\hline $\begin{array}{l}\text { Buchta, } 2017 \text { [17]; } \\
n=842\end{array}$ & $\begin{array}{l}\text { - Number of follow-up visits } \\
\text { - Number of hospitalisations } \\
\text { - Mean costs for the healthcare } \\
\text { provider }\end{array}$ & $\begin{array}{l}\text { - No difference in the number of follow-up visits or hospitalisations } \\
\text { was noted between groups ( } p \text {-value was insignificant) } \\
\text { - The costs turned out to be on average } 33.5 \% \text { lower in the } \\
\text { telemonitored arm compared to the standard group }(p<0.001)\end{array}$ \\
\hline $\begin{array}{l}\text { Kurek, } 2017[17] \\
\text { (COMMIT-HF); } \\
n=574\end{array}$ & $\begin{array}{l}\text { - Number of outpatient visits } \\
\text { - Number of hospitalisations } \\
\text { due to worsening of heart } \\
\text { failure }\end{array}$ & $\begin{array}{l}\text { - Reduction of the number of outpatient visits was noted } \\
\text { in the remotely monitored group during 3-year follow-up } \\
\text { ( } 6.41 \text { vs. } 7.52 \text { visits; } p=0.02 \text { ) } \\
\text { - The trial did not demonstrate the decreased percentage } \\
\text { of hospitalisations between groups ( } p=0.27 \text { after } 1 \text { year; } \\
p=0.63 \text { after } 3 \text { years) }\end{array}$ \\
\hline $\begin{array}{l}\text { Bogyi, } 2019[23] \\
n=231\end{array}$ & Total number of visits & $\begin{array}{l}\text { - Increased number of visits in a heart failure outpatient clinic among } \\
\text { remotely monitored patients ( } 1.9 \text { vs. } 1.1 \text { visits per patient per year; } \\
p=0.003) \text {, though the total number of appointments did not differ } \\
\text { significantly }(p=0.08)\end{array}$ \\
\hline
\end{tabular}

CV hospitalisation - cardiovascular hospitalization, ICD - implantable cardioverter-defibrillator, LOS in hospital - length of stay in hospital, $n$-number of patients studied, $p$ - level of statistical significance 
may lead to a delayed diagnosis of new symptoms and complications. Hence health care providers should give more attention to planning follow-up visits properly.

Furthermore, processing and evaluating the transmitted data requires qualified personnel. In the majority of cases, a group responsible for supervision consists of a nurse and two medical practitioners (an organisation system based on the HomeGuide Model) [29]. It is anticipated that in the future specially educated technicians will play a larger part in telemonitoring [18]. Finding adequate staff to manage a monitoring centre might be an issue that will limit the development of this form of treatment. The development of effective algorithms is necessary in order to assure quick and well-organized responses to recorded abnormalities [3]. Similarly to other technological innovations, the broad implementation of telemonitoring systems is expensive. Devices with data transmission function cost $5-20 \%$ more than standard implants. In many countries, methods of remote control are not reimbursed $[29,30]$.

In conclusion, telemonitoring of CIED has many positive aspects, such as lower mortality rate, faster diagnosis and clinical decision, fewer visits, hospitalisations, and the shorter time of hospitalisation that leads to lower costs for both the health care system and patients. Like every novel method, it has limitations, due to higher costs of devices with the built-in function of data transmission, lack of reimbursement, and scarcity of qualified personnel responsible for the supervision of telemonitoring centres. Further research is needed to establish efficient and safe algorithms as a response to the transferred data.

\section{GERIATRIC CARDIOLOGICAL PATIENTS' TELESUPERVISION}

In recent years, many researchers have started to implement home telesupervision and telecare systems in patients aged 65 years and over. It is assumed that this may increase the possibility of monitoring the patients' health, protect them from being re-hospitalized, extend their lifespan and improve their quality of life [5, 31]. There are articles stating that the number of hospitalizations or mortality rate of patients does not change $[32,33]$ while others report that the number of hospital admissions is lower and life expectancy increases [34]. Such discrepancies might result from the fact that the studies often also include people under 65 , which may not completely illustrate the existing situation or may distort the interpretation of the results [35]. Lelli et al. performed a meta-analysis of studies which included only people aged over 65 (average age 76.8 years) with heart failure to determine whether telesupervision of elderly patients reduces overall mortality rate, the necessity of hospitalization due to this disease and the number of visits to the casualty department. It was found that only the number of repeated hospital admissions due to heart failure decreased statistically signifi- cantly while health telemonitoring did not have a significant impact on the other parameters [35]. However, it was noted that most rehospitalisations were caused by other diseases (mainly cardiovascular and diabetes) which were not remotely monitored and could directly result in death $[35,36]$.

Comparing the advantages and disadvantages of using constant cardiac telemedicine, it seems that medical telesupervision can be helpful for elderly cardiac patients. However, more research is needed to determine which group of patients will benefit the most from this technology [35]. In general, it is emphasised that both the interest of the patients and the level of following the instructions given to them by the medical staff are rather high. Patient satisfaction was also found to remain high. Additionally, it has been observed that the overall understanding of symptoms resulting from heart failure has increased and that the monitored patients' sense of security has increased [37]. However, during any technical issues not caused by the patient, a pattern has been observed. The supervised person became stressed and started following recommendations less frequently [38]. Lynga et al. in such cases suggest sending reassuring feedback to the patients to confirm that they have followed the instructions correctly [39].

Unfortunately, there is no strong evidence that the telemonitored elderly patients have an extended lifespan compared to non-telemonitored patients. Many studies include people under the age of 65 , which has proven to be more difficult to interpret. Cardiac telemedicine has proved to be a helpful tool for both the patients and the medical personnel, but further research is needed.

\section{TELEREHABILITATION OF CARDIAC PATIENTS}

The studies confirm a high level of safety of cardiac telerehabilitation (CTR) including in people belonging to high-risk groups. Furthermore, it has been shown that CTR is at least as effective as standard training, and it has better attendance and a higher percentage of completed exercise schedules when compared to the standard form of rehabilitation [40]. The purpose of CTR is to provide patients with an opportunity to exercise at home and without exposing the patient to dangers caused by overtraining and exhaustion. At the same time, the workout should be demanding enough to gain effects such as improved condition. Constant contact with the specialist and remote monitoring of the patient's actions are vital $[5,41]$.

The person to be supervised is lent inter alia an external ECG recorder, which is coordinated with the performed exercises. Its job is to examine the electrical activity of the heart before, at a given moment during and after the training as well as to send the gathered data to the monitoring centre. There is also an option to conduct another examination manually if the patient experiences any worrying symptoms of exhaustion. As mentioned, the device works in a so-called loop, which allows 


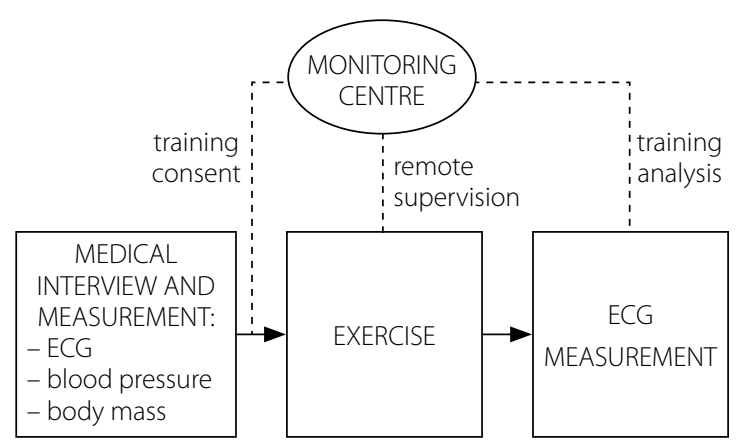

FIGURE 1. A scheme of a training session at the basic stage of cardiac telerehabilitation $[5,41]$

the responsible specialist to obtain the ECG records from before the intervention. Another feature of the apparatus is the ability to manage the convalescent's actions with audio and visual signals. During the training, the patient can use other pieces of technology such as a manometer, scales, a pulse-oximeter, a laptop and a mobile phone. The latter two transfer the data and provide continuous contact with the medical professional via the cellular network or the Internet $[5,40]$.

To conduct CTR a medical team consisting of a doctor, a physiotherapist, a psychologist and a nurse or an ECG engineer is necessary. Their duties cover educating the patient about their disease and the course of the rehabilitation, planning and conducting training sessions, analysis of the obtained data (and reacting to potential threats) and psychological support. Cardiac telerehabilitation can be divided into two stages: an initial and a basic stage. The former is conducted in a hospital or another medical unit and lasts one or two weeks during which the convalescent is initially examined and their clinical state and condition are evaluated. The patient receives instructions covering the equipment used as well as the way CTR works. Based on their results of cardio-pulmonary tests there is prepared an individual exercise schedule considering the sequence of physical activity and rest [5].

The basic stage of CTR is the regular rehabilitation (Fig. 1). Each training session comprises two phases. Prior to starting the exercise the patient contacts the monitoring centre via a mobile phone and answers a series of questions regarding their health state, condition and taken medications. Then they perform and send an ECG record, values of blood pressure and a body mass reading. After analysing the received information the rehabilitator decides whether to give permission for the physical activity. Having been granted permission the convalescent begins the second phase of the training session, which is telemonitored physical exercise divided into the following types: aerobic endurance, breathing, resistance, callisthenics and coordination training. It is recommended that the convalescent be accompanied by a close person who has been taught first aid [42]

At the end of the training session, an ECG record is performed and transmitted. The medical team anal- yses the results and evaluates safety and effectiveness of the particular training $[5,41]$.

The rate of condition improvement and the patient's satisfaction, as well as adherence to the exercise schedule, are analysed in both types of CTR (and standard form). The parameters used for comparison are: results in fitness tests (6-minute walk distance, cardiopulmonary exercise test), readings of oxygen consumption, attendance at training sessions as well as results of surveys covering the patients' acceptance of the form of training and health-related quality of life [40, 42].

Reports have shown that the standard form of rehabilitation in e.g. a hospital is not always taken up by the patients due to e.g. the cost of transport to/from the place of rehabilitation, lack of comfort during travelling, unsuitable rehabilitation schedules and unwillingness to participate in group exercises [41]. Piotrowicz et al. reported that CTR provides personal comfort to the patient [42]. However, previously published results have shown that CTR involving a certain degree of contact between patients ('group' rehabilitation) is beneficial to their involvement in physical training. For example, Hwang et al. [40] developed a system of group telerehabilitation where the communication with the monitoring centre was led via teleconferencing software using the Internet connection. Moreover, these authors have shown that the training session safety was high, the rehabilitator's impact on the exercising people was optimised and the patients engagement was excellent, while those involved reported that they appreciate the company of others [40].

Potential disadvantages of this form of training are technical difficulties in use of the telemonitoring equipment by the patients and a lack of direct contact with the rehabilitator. The distance also has a negative impact on the health professionals as instant help in case of an emergency is impossible. In terms of the health care system, the obstacles inhibiting widespread development of CTR can include additional costs due to the purchase of new technologies necessary for telemonitoring and the need to train the medical staff [5].

To sum up, CTR is a promising method, which shows great potential. It is safe and achieves results comparable with those of the traditional form of rehabilitation. Moreover, patients usually appreciate telerehabilitation more than stationary methods. However, CTR faces a few obstacles that make it more challenging to implement it to regular schemes of therapy widely. Further research is required to provide possible solutions to organisational and financial issues.

\section{TELE-EDUCATION IN CARDIOLOGY}

Rapid technological progress has enabled knowledge to be shared remotely. It has been used in medical education inter alia in cardiology to improve existing ways of teaching (Table 2). Tele-education enables unified knowledge to be communicated by the best lecturers 
Telemedicine in cardiology - prospects, risks and health inequalities

to a large group of people (health care professionals, medical students, patients and their family). There is evidence that an average patient who has undergone a myocardial infarction does not stay long enough in a hospital to obtain all the necessary knowledge about the proper way of living. It was proved that 6-month long support (by telephone) leads to an increase of convalescent physical activity and gives a chance that a higher percentage of them e.g. stop smoking [43].

Care for the mental health of cardiac patients is also very important. Cardiovascular diseases are associated with a high level of fear of death. Saki et al. reported that education using technology reduces anxiety in post-myocardial infarction patients [44]. Panic attacks occur to people even awaiting coronary angiography - as early as at the stage of examination used to diagnose the disorder with the aim of precise treatment of ischaemic heart disease. The findings of analyses suggest that education involving video footage is an effective technique in dealing with a fear of this procedure. A specially produced film that included information about the human heart, the disease and the treatment significantly decreased patients' level of stress [45].

A vital group of people at risk of developing CVD are athletes of different ages. Aiming for better results they tend to take substances that boost their physical efficiency, which leads to improper work of the heart. Therefore actions that increase awareness about the harmfulness of doping are essential [46]. Tele-education can prove to be a useful tool in this case. For example, the game Heart at Risk innovatively teaches which products improving physical parameters are inappropriate for the physiology of the heart [47].

It remains questionable whether e-learning in cardiology is more efficient than the traditional methods of teaching. Admittedly, research done by Gökçe and Arslan showed that video reduces stress to a greater extent than transmitting knowledge using brochures to read [45]. On the other hand, in the scientific literature, it can be found that e-teaching does not mean achieving better results than the conventional way of sharing knowledge $[44,48]$. An important debatable subject is using tele-education in order to teach practical skills. For instance, Viljoen et al. suggest that there is not enough evidence to claim that instruction using a computer is the best way of training students in the field of EKG. A combined form is favoured, based on traditional learning with a teacher enriched with multimedia courses which consolidate students' knowledge [49].

Remote learning involves some challenges. It is essential to provide specialized staff with training to prepare didactic materials suitable for a particular group of people (especially with overweight/obesity, diabetes, depression - major risk factors of dangerous complications of various cardiovascular diseases) [4]. It should also be taken into consideration that not everybody has access to the hard-
TABLE 2. Examples of tele-education in cardiology $[5,47]$

\begin{tabular}{|l|c|}
\hline Forms of tele-education & Examples \\
\hline Mobile apps and games & $\begin{array}{c}\text { MyHeart Counts } \\
\text { Heart at risk }\end{array}$ \\
\hline Websites & YouTube \\
\hline Portals for patient & $\begin{array}{c}\text { www.heart.org } \\
\text { www.healthline.com }\end{array}$ \\
\hline Virtual reality & Anatomy 4D \\
\hline
\end{tabular}

ware used in e-teaching. Some people avoid technology and learn much better from conventional sources [50].

The scientific literature is not in complete agreement whether tele-education is better than the conventional way of sharing knowledge. However, various examples show the great potential of e-teaching in cardiology. Moreover, it enables unified knowledge to be communicated by the best lecturers to a large group of people. Remote learning involves some challenges that should be taken into consideration.

\section{CONCLUSIONS}

According to the review of the literature, it should be highlighted that cardiological teleconsultations are playing an increasingly important role in the health care system and can be utilised not only during the COVID-19 pandemic. This brings obvious benefits such as quick diagnosis, the shorter time period between reporting symptoms and taking up treatment, providing additional data facilitating the doctor's decisions and reduction in costs (Table 3 ). At the same time, new, more efficient technological innovations such as the Internet, specialised software or algorithms using artificial intelligence enable easier implementation of telemedical systems including those dedicated to cardiological care. Electrocardiogram telemonitoring is one of the basic telecardiological tools which make it possible to make faster and more accurate diagnoses than the standard procedure. Moreover, it extends the possibilities to monitor the treatment effectiveness and to implement changes without the necessity of the patient's frequent visits to health care units. Systems of remote monitoring of CIED are a significant solution whose further development, improvement and research help to refine the monitoring of heart failure patients. The culmination of the former actions is telerehabilitation, which provides similar results as stationary rehabilitation but at the same time ensures better comfort of the convalescent. Telerehabilitation, telesupervision and cardiological teleconsultations also have potential drawbacks caused mostly by difficulties in financing and practical implementation in case of a lack of direct contact between the staff and the patient. Thus it is advised to concentrate on increasing the availability of these forms of support and providing telemonitoring devices that are as intuitive to use as possible, because the number of people over 65 is still rising 
TABLE 3. Potential advantages and disadvantages of cardiological telemedicine vs. traditional medical care $[2,5-17,22-38$, $41,42,49,50]$

\begin{tabular}{|c|c|}
\hline Advantages & Disadvantages \\
\hline \multicolumn{2}{|c|}{ Medical aspect } \\
\hline $\begin{array}{l}\text { - Reduction of the number of outpatient visits } \\
\text { - Reduction of total urgent in-office visits } \\
\text { - Shortening of door-to-balloon time (from admission } \\
\text { on ER to heart catheterisation) as well as the time } \\
\text { between detection of an emergency state and the } \\
\text { intervention } \\
\text { - Decrease in mortality rate of cardiac patients } \\
\text { - Online professional meetings among international } \\
\text { experts are useful to share knowledge and support } \\
\text { decision making regarding care provided to patients } \\
\text { - Reduction of the hospitalisation necessity due to } \\
\text { cardiac disease and the number of visits to the casualty } \\
\text { department } \\
\text { - The increase of common understanding of symptoms } \\
\text { resulting from cardiac failure due to tele-education; } \\
\text { a significantly larger number of people can access } \\
\text { professional sources of knowledge } \\
\text { - Better attendance and a higher percentage of comple- } \\
\text { ted exercise schedules during cardiac telerehabilitation }\end{array}$ & $\begin{array}{l}\text { - Lack of direct contact between the medical staff } \\
\text { and the patient (e.g. infeasible physical examination } \\
\text { leading to a risk of bad diagnosis and improper treat- } \\
\text { ment decision) } \\
\text { - Rarely conducted interviews and physical examination } \\
\text { may lead to a delayed diagnosis of new symptoms and } \\
\text { complications } \\
\text { - Higher number of unplanned remote visits (due to } \\
\text { patient uncertainty or general malaise of the telemoni- } \\
\text { tored people) } \\
\text { - Potential cardiac patient exposure to dangerous } \\
\text { overtraining and exhaustion during telerehabilitation } \\
\text { (a close person who knows first aid is recommended } \\
\text { to accompany the convalescent as instant professional } \\
\text { help is impossible) }\end{array}$ \\
\hline \multicolumn{2}{|c|}{ Social aspect } \\
\hline $\begin{array}{l}\text { - Cardiac patients' significant general satisfaction and } \\
\text { the feeling of security with remote medical care } \\
\text { - Financial benefits for patients (lower cost of transport } \\
\text { to the place of medical consultation and/or rehabilita- } \\
\text { tion), which makes it less daunting for them to begin } \\
\text { the therapy } \\
\text { - Reduction of the total costs of diagnostics, treatment, } \\
\text { rehabilitation or absence from the convalescents' work } \\
\text { - Lower hospitalisation cost per patient-year } \\
\text { - Lower mean costs for the health care system }\end{array}$ & $\begin{array}{l}\text { - Mental barrier (especially among geriatric population } \\
\text { - some people avoid technology and prefer treatment/ } \\
\text { learning through conventional methods rather than } \\
\text { telemedicine/tele-education) } \\
\text { - Mental stress resulting from more frequent patients' } \\
\text { confrontation with their diseases }\end{array}$ \\
\hline \multicolumn{2}{|c|}{ Technical aspect } \\
\hline $\begin{array}{l}\text { - An ability to easily gather large amounts of relevant } \\
\text { information (the data collected and transmitted from } \\
\text { the medical devices installed on a patient) } \\
\text { - Faster therapy (remote monitoring is intended to } \\
\text { shorten the period of time between the occurrence of } \\
\text { a cardiological abnormality and a clinical decision) } \\
\text { - Utilisation of different technical innovations } \\
\text { - Time benefits for patients (transport, waiting for medi- } \\
\text { cal staff) } \\
\text { - Better attendance and a higher percentage of comple- } \\
\text { ted exercise schedules during cardiac telerehabilitation }\end{array}$ & $\begin{array}{l}\text { - Requirement of proper devices, hardware, software } \\
\text { - Medical personnel and patients must be trained to } \\
\text { gain appropriate knowledge and competence to use } \\
\text { the latest technology } \\
\text { - An organizational barrier (data transmission, further } \\
\text { processing can be done automatically via specialized } \\
\text { software based on artificial intelligence algorithms } \\
\text { or traditionally through a doctor's/professional staff } \\
\text { analysis). } \\
\text { - Risk of loss of the gathered data due to a software/har- } \\
\text { dware malfunction } \\
\text { - The need of an advanced security system to prevent } \\
\text { leakage of confidential medical data } \\
\text { - High cost of a telemonitoring system (large techno- } \\
\text { logical resolution devices; hardware, software) and } \\
\text { difficulties with reimbursement in many countries }\end{array}$ \\
\hline
\end{tabular}




\begin{tabular}{|l|}
\hline \multicolumn{1}{|c|}{ Advantages Disadvantages } \\
\hline \multicolumn{1}{|c|}{ Difficult opinion - advantage/disadvantage } \\
\hline - Length of stay in a hospital (shorter or similar times) \\
- General increase of staff and patient anxiety in the aspect of bad diagnosis and improper treatment but the decre- \\
ase in anxiety of patients with implantable devices for cardiac resynchronization therapy, related to the abnormal \\
heartbeat and its pathophysiological implications (e.g. myocardial infarction) \\
- Using e-teaching/e-learning does not mean that cardiac patients/students will achieve better results than the \\
conventional way of sharing knowledge (especially in the practical aspect), so a combined form of education \\
(remote and traditional) is favoured \\
- Lack of motivation to telerehabilitation (mainly personally dependent) \\
- Total costs for patients (mainly dependent on the telemedicine systems used) \\
- Time benefits for medical staff, patients, and their families (mainly dependent on the kind of cardiac diseases, \\
personal aspects)
\end{tabular}

in society, and as a result, so is the percentage of patients requiring cardiological help.

There remains an unanswered question whether teleconsultations, telesupervision and telerehabilitation can become the dominant methods of preventing CVD or alleviating their course. As there is no clear answer, further research is needed. It may identify the preferred groups of cardiac patients and indicate the most appropriate moment of their lives to implement proper health telemonitoring for every situation. It seems that using certain cardiac telesupervision devices is becoming easier, which is crucial for their operation by the elderly and the disabled. Remote education in cardiology still remains a promising form of teaching that removes numerous barriers. It gives a chance of successfully educating patients, medical students, the medical staff of different specialities and even the whole society thanks to removing restrictions such as distance and shortage of personnel. The advantages mentioned above, especially after removing certain barriers, suggest that teleconsultations, telesupervision of various groups of patients by using remote ECG records, systems of controlling the CIED and other devices or software as well as telerehabilitation and e-learning may together lead to a large step in modifying not only cardiology but also the whole health care system. It appears that the wider introduction of these technologies has already contributed to lowering the mortality rate of cardiovascular diseases, which still are major causes of deaths worldwide.

Telemedical innovations bring many promising possibilities in favour of cardiac patients. However, there are still significant difficulties in their wider implementation. Further research in the future may provide answers to common issues and even find ways to emphasise the already apparent assets of telemedicine. Possible paths of studies on the topic are presented in Table 3.

\section{DISCLOSURE}

The authors report no conflicts of interest.

\section{References}

1. Johnson K, Torres Soto J, Glicksberg B, et al. Artificial intelligence in cardiology. J Am Coll Cardiol 2018; 71(23): 2668-2679.

2. Constantinides PA, Fitzmaurice D. Artificial intelligence in cardiology: applications, benefits and challenges. Br J Cardiol 2018: 25(3): 86-87.

3. Braunschweig F, Anker SD, Proff J, Varma N. Remote monitoring of implantable cardioverter-defibrillators and resynchronization devices to improve patient outcomes: dead end or way ahead? Europace 2019; 21(6): 846-855.

4. Fatyga E, Dzięgielewska-Gęsiak S, Wierzgoń A, et al. The coronavirus disease 2019 pandemic: telemedicine in elderly patients with type 2 diabetes. Pol Arch Intern Med 2020; 130 (5): 452-454.

5. Piotrowicz R, Krzesiński P, Balsam P, et al. Cardiology telemedicine solutions - opinion of the experts of the Committee of Informatics and Telemedicine of Polish Society of Cardiology, Section of Non-invasive Electrocardiology and Telemedicine of Polish Society of Cardiology and Clinical Sciences C-full version, 2018. Available from: https://www.ptkardio.pl/pobierz/958349a9e0526a185419f8e4b612e572/ (accessed: 20 April 2021).

6. Baig MM, GholamHosseini H, Moqeem AA, et al. A systematic review of wearable patient monitoring systems - current challenges and opportunities for clinical adoption. J Med Syst 2017; 41(7): 115.

7. Cinaglia P, Tradigo G, Guzzi PH, et al. Design and implementation of a telecardiology system for mobile devices. Interdiscip Sci 2015; 7(3): 266-274.

8. Rao NH, Pandya M, Prasad MVVK. An evaluation of data security for telemedicine application development. Int J Comput Appl 2013; 79(1): 21-25.

9. Marcolino MS, Maia LM, Oliveira JAQ, et al. Impact of telemedicine interventions on mortality in patients with acute myocardial infarction: a systematic review and meta-analysis. Heart 2019; 105(19): 1479-1486.

10. Halcox JPJ, Wareham K, Cardew A, et al. Assessment of remote heart rhythm sampling using the AliveCor Heart Monitor to 
screen for atrial fibrillation. Circulation 2017; 136(19): 17841794.

11. Marcolino MS, Santos TMM, Stefanelli FC, et al. Cardiovascular emergencies in primary care: An observational retrospective study of a large-scale telecardiology service. Sao Paulo Med J 2017; 135(5): 481-487.

12. Koole MAC, Kauw D, Winter MM, et al. First real-world experience with mobile health telemonitoring in adult patients with congenital heart disease. Neth Heart J 2019; 27(1): 30-37.

13. Majumder S, Chen L, Marinov O, et al. Noncontact wearable wireless ECG systems for long-term monitoring. IEEE Rev Biomed Eng 2018; 11: 306-321.

14. Wang L-H, Zhang W, Guan M-H, et al. A low power high-data-transmission multi-lead ECG acquisition sensor system. Sensors (Basel) 2019; 19(22): 4996.

15. Slotwiner D, Varma N, Akar JG, et al. HRS Expert Consensus Statement on remote interrogation and monitoring for cardiovascular implantable electronic devices. Heart Rhythm 2015; 12(7): e69-e100.

16. Raatikainen MJP, Arnar DO, Zeppenfeld K, et al. Statistics on the use of cardiac electronic devices and electrophysiological procedures in the European Society of Cardiology countries: 2014 report from the European Heart Rhythm Association. Europace 2015; 17(Suppl 1): i1-i75.

17. Buchta P, Tajstra M, Kurek A, et al. The impact of remote monitoring of implanted cardioverter-defibrillator (ICD) and cardiac resynchronisation therapy device (CRT-D) patients on healthcare costs in the Silesian population: three-year follow-up. Kardiol Pol 2017; 75(6): 573-580.

18. Zanotto G, D’Onofrio A, Della Bella P, et al. Organizational model and reactions to alerts in remote monitoring of cardiac implantable electronic devices: a survey from the Home Monitoring Expert Alliance project. Clin Cardiol 2019; 42(1): 76-83.

19. Zartner PA, Toussaint-Goetz N, Photiadis J, et al. Telemonitoring with implantable electronic devices in young patients with congenital heart diseases. Europace 2012; 14(7): 1030-1037.

20. De Ruvo E, Sciarra L, Martino AM, et al. A prospective comparison of remote monitoring systems in implantable cardiac defibrillators: potential effects of frequency of transmissions. J Interv Card Electrophysiol 2016; 45(1): 81-90.

21. Kurek A, Tajstra M, Gadula-Gacek E, et al. Impact of remote monitoring on long-term prognosis in heart failure patients in a real-world cohort: Results from all-comers COMMIT-HF trial. J Cardiovasc Electrophysiol 2017; 28(4): 425-431.

22. Lin $\mathrm{M}-\mathrm{H}$, Yuan $\mathrm{W}-\mathrm{L}$, Huang, T-Ch, et al. Clinical effectiveness of telemedicine for chronic heart failure: A systematic review and meta-analysis. J Investing Med 2017; 65(5): 899-911.

23. Bogyi P, Vamos M, Bari Z, et al. Association of remote monitoring with survival in heart failure patients undergoing cardiac resynchronization therapy: retrospective observational study. J Med Internet Res 2019; 21(7): e14142.

24. Crossley GH, Boyle A, Vitense H, et al. The CONNECT (Clinical Evaluation of Remote Notification to Reduce Time to Clinical Decision) trial: the value of wireless remote monitoring with automatic clinician alerts. J Am Coll Cardiol 2011; 57(10): 1181-1189.
25. Ricci RP, Vicentini A, D'Onofrio A, et al. Economic analysis of remote monitoring of cardiac implantable electronic devices: results of the health economics evaluation registry for remote follow-up (TARIFF) study. Heart Rhythm 2017; 14(1): 50-57.

26. Hindricks G, Elsner C, Piorkowski C, et al. Quarterly vs. yearly clinical follow-up of remotely monitored recipients of prophylactic implantable cardioverter-defibrillators: Results of the REFORM trial. Eur Heart J 2014; 35(2): 98-105.

27. Dario C, Luisotto E, Dal Pozzo E, et al. Assessment of patients' perception of telemedicine services using the service user technology acceptability questionnaire. Int J Integr Care 2016; 16(2): 13 .

28. Landolina M, Perego GB, Lunati M, et al. Remote monitoring reduces healthcare use and improves quality of care in heart failure patients with implantable defibrillators: the evolution of management strategies of heart failure patients with implantable defibrillators (EVOLVO) study. Circulation 2012; 125(24): 2985-2992.

29. Lau C-P, Zhang S. Remote monitoring of cardiac implantable devices in the Asia-Pacific. Europace 2013; 15(Suppl 1): i65-i68.

30. Palmisano P, Melissano D, Zanotto G, et al. Change in the use of remote monitoring of cardiac implantable electronic devices in Italian clinical practice over a 5-year period: results of two surveys promoted by the AIAC (Italian Association of Arrhythmology and Cardiac Pacing). J Cardiovasc Med (Hagerstown) 2020; 21(4): 305-314.

31. Zulfiqar AA, Hajjam A, Gény B, et al. Telemedicine and cardiology in the elderly in France: inventory of experiments. Adv Prev Med 2019; 2019: 2102156.

32. Olivari Z, Giacomelli S, Gubian L. et al. The effectiveness of remote monitoring of elderly patients after hospitalisation for heart failure: the renewing health European project. Int J Cardiol 2018; 257: 137-142.

33. Kraai I, de Vries A, Vermeulen K, et al. The value of telemonitoring and ICT-guided disease management in heart failure: results from the IN TOUCH study. Int J Med Inform 2016; 85(1): 53-60.

34. Inglis SC, Clarkm RA, Dierckx R, et al. Structured telephone support or non-invasive telemonitoring for patients with heart failure. Cochrane Database Syst Rev 2015; CD007228.

35. Lelli D, Incalzi RA, Adiletta V, Pedone C. Is telemonitoring effective in older adults affected by heart failure? A meta-analysis focused on this population. J Gerontol 2019; 67(2): 87-95.

36. Chamberlain AM, Dunlay SM, Gerber Y, et al. Burden and timing of hospitalizations in heart failure: a community study. Mayo Clin Proc 2017; 92(2): 184-192.

37. Fairbrother P, Ure J, Hanley J, et al. Telemonitoring for chronic heart failure: the views of patients and healthcare professionals a qualitative study. J Clin Nurs 2013; 23(1-2): 132-144.

38. Lynga P, Fridlund B, Langius-Eklof A, Bohm K. Perceptions of transmission of body weight and telemonitoring in patients with heart failure? Int J Qual Stud Health Well-being 2013; 8: 21524.

39. Lynga P, Persson H, Hagg-Martinell A, et al. Weight monitoring in patients with severe heart failure (WISH): a randomized controlled trial. Eur J Heart Fail 2012; 14(4): 438444. 
40. Hwang R, Bruning J, Morris NR, et al. Home-based telerehabilitation is not inferior to a centre-based program in patients with chronic heart failure: a randomised trial. J Physiother 2017; 63(2): 101-107.

41. Neubeck L, Freedman SB, Clark AM, et al. Participating in cardiac rehabilitation: a systematic review and meta-synthesis of qualitative data. Eur J Prev Cardiol 2011; 19(3): 494-503.

42. Piotrowicz E, Zieliński T, Bodalski R, et al. Home-based telemonitored nordic walking training is well accepted, safe, effective and has high adherence among heart failure patients, including those with cardiovascular implantable electronic devices: a randomised controlled study. Eur J Prev Cardiol 2015; 22(11): 1368-1377.

43. Hanssen TA, Nordrehaug JE, Eide GE, Hanestad BR. Improving outcomes after myocardial infarction: a randomized controlled trial evaluating effects of a telephone follow-up intervention. Eur J Cardiovasc Prev Rehabil 2007; 14(3): 429-437.

44. Saki A, Bahabadi AH, Noghabi AAA, Mehran A. Comparison of face-to-face and electronic education methods on anxiety in patients with acute myocardial infarction. HAYAT 2014; 20(1): 6-14

45. Gökçe E, Arslan S. Possible effect of video and written education on anxiety of patients undergoing coronary angiography. J Perianesth Nurs 2019; 34(2): 281-288.

46. La Gerche A, Brosnan MJ. Drugs in sport - a change is needed, but what? Heart Lung Circ 2018; 27(9): 1099-1104.

47. Da Silva HC, de Miranda ÊF, de Andrade MC, et al. Heart at risk: electronic educational game with information on doping in athletes. Rev Bras Med Esporte 2019; 25(5): 379-383.

48. Vaona A, Banzi R, Kwag KH, et al. E-learning for health professionals. Cochrane Database Syst Rev 2018; 1(1): CD011736.

49. Viljoen CA, Scott Millar R, Engel ME. Is computer-assisted instruction more effective than other educational methods in achieving ECG competence amongst medical students and residents? A systematic review and meta-analysis. BMJ Open 2019; 9(11): e028800

50. Gogia SB. Fundamentals of telemedicine and telehealth. Elsevier Science Ltd., Oxford 2019.

51. Piccini JP, Mittal S, Snell J, et al. Impact of remote monitoring on clinical events and associated health care utilization: A nationwide assessment. Heart Rhythm 2016; 13(12): 2279-2286.

\section{AUTHORS' CONTRIBUTIONS}

TG prepared the concept of the paper. All authors analysed data, interpreted them and wrote the article. TG and VN critically revised and finally approved it. 